Article

\title{
Improved Dielectric Breakdown Strength of Polyimide by Incorporating Polydopamine-Coated Graphitic Carbon Nitride
}

\author{
Yinjie Dong, Zhaoyang Wang, Shouchao Huo, Jun Lin and Shaojian He *D \\ State Key Laboratory of Alternate Electrical Power System with Renewable Energy Sources, \\ North China Electric Power University, Beijing 102206, China; ddxdyj@126.com (Y.D.); \\ wang94269264@163.com (Z.W.); huo472@foxmail.com (S.H.); jun.lin@ncepu.edu.cn (J.L.) \\ * Correspondence: heshaojian@ncepu.edu.cn
}

check for updates

Citation: Dong, Y.; Wang, Z.; Huo, S.; Lin, J.; He, S. Improved Dielectric Breakdown Strength of Polyimide by Incorporating Polydopamine-Coated Graphitic Carbon Nitride. Polymers 2022, 14, 385. https://doi.org/ $10.3390 /$ polym 14030385

Academic Editor: Jin-Hae Chang

Received: 9 December 2021

Accepted: 12 January 2022

Published: 19 January 2022

Publisher's Note: MDPI stays neutral with regard to jurisdictional claims in published maps and institutional affiliations.

Copyright: (C) 2022 by the authors. Licensee MDPI, Basel, Switzerland. This article is an open access article distributed under the terms and conditions of the Creative Commons Attribution (CC BY) license (https:// creativecommons.org/licenses/by/ $4.0 /)$.

\begin{abstract}
Breakdown strength is an important parameter for polymer dielectric, and introducing inorganic filler into the polymer matrix is an efficient method to improve the breakdown strength. In this work, graphitic carbon nitride nanosheets (CNNS) were ultrasonically exfoliated and coated with polydopamine to obtain modified nanosheets (DCNNS), and then polyimide (PI) composite films with various CNNS and DCNNS were prepared and compared. Owing to the abundant hydroxyl groups of polydopamine, good filler-polymer compatibility and uniform filler dispersion were achieved for PI/DCNNS composites. Both breakdown strength and dielectric constant were improved with the addition of either CNNS or DCNNS. However, at the same filler content, the PI/DCNNS composites exhibited higher breakdown strength and dielectric constant than the PI/CNNS. The PI composite with $0.5 \mathrm{wt} \%$ DCNNS showed the highest breakdown strength of $\sim 300 \mathrm{kV} / \mathrm{mm}$, increased by $67.6 \%$ as compared to the pure PI, while the PI/CNNS composite with the same filler content only increased by $14.5 \%$.
\end{abstract}

Keywords: polyimide; graphitic carbon nitride nanosheets; polydopamine; interfacial interaction; breakdown strength

\section{Introduction}

Polymer dielectrics with good dielectric properties and high-energy storage density play an important role in modern information and electronic industries connected to, for example, charge storage devices and embedded capacitors [1,2]. However, with the rapid development of the modern power industry, more requirements are proposed on the stability of polymer dielectrics and electronic devices operating under high electrical conditions. For the insulation dielectric materials, once the surface flashover or body breakdown phenomenon occurs, it can lead to insulation dielectric surface degradation and an equipment short circuit, ultimately threatening the operational reliability of the power equipment. What is more, according to the formula of energy storage density of the linear polymer, $U=\frac{1}{2} \varepsilon_{0} \varepsilon_{r} E_{b}^{2}$, the energy storage density $(U)$ is proportional to the square of breakdown strength $\left(E_{b}\right)$ tolerated by the film, so it is of great significance to improve the breakdown strength of polymer in the power industry [3,4].

Polyimide (PI), as a typical engineering polymer material, has been widely used in insulation materials, microelectronics, aerospace and other fields in recent years due to its high thermal stability, excellent electrical insulation, and mechanical properties [5-7]. However, the defects (such as impurities and micro-pores) during the breakdown of pure PI will lead to a theoretical reduction in the actual breakdown strength of the material, which limits its demand in some special applications [8]. The traditional strategy of adding inorganic nanofillers (such as $\mathrm{Al}_{2} \mathrm{O}_{3}[9,10]$ and $\mathrm{BaTiO}_{3}[11]$ ) to the polymer matrix can improve the comprehensive properties of the composites and suppress the distorted electric field. However, the small particle size and large specific surface area of conventional 
nanoparticles lead to their poor dispersion in polymers. Recently, it was reported that twodimensional nanofillers [12-19], such as boron nitride, graphene, mica and titanium dioxide nanosheets, play an important role in improving the performance, including the breakdown field strength, of polymer composites when they are evenly dispersed in the matrix.

Two-dimensional graphitic carbon nitride $\left(\mathrm{g}-\mathrm{C}_{3} \mathrm{~N}_{4}\right)$ is a promising material commonly used in the fields of photocatalysis and heterogeneous catalysis due to its simple synthesis and low cost [20-22]. Recently, Zhu et al. [23] reported that the frictional properties of the composites were improved by introducing $\mathrm{g}-\mathrm{C}_{3} \mathrm{~N}_{4}$ as a filler in the polyimide matrix. This work provides an example of the application of $\mathrm{g}-\mathrm{C}_{3} \mathrm{~N}_{4}$ as an excellent nanofiller in polymer-based composites. Wang et al. [24] explored the potential application of carbon nitride nanosheets in improving the thermal conductivity of PI through experiments and simulations. The improvement in thermal conductivity benefited from the self-orientation and strong interaction of the fillers, along with the PI film. Although $g-\mathrm{C}_{3} \mathrm{~N}_{4}$ has been used as a filler to improve polymers' properties, the research on its application as an electrical insulation filler in the field of high-voltage insulation is relatively rare [25]. Generally, the poor interfacial compatibility between the polymer matrix and the filler affects the dielectric breakdown strength of composites [26-28]. To solve this problem, an economical, efficient and easy way is to modify the inorganic fillers through surface treatment, modulating the interfacial properties and increasing the breakdown field strength of the composite dielectric. In our previous work [25], silicone rubber (SR)/g- $\mathrm{C}_{3} \mathrm{~N}_{4}$ composites were prepared by in situ modification with vinyl tri-methoxysilane (VTMS), and the incorporation of VTMS reduced the defects in the prepared composites and improved their breakdown strength and mechanical properties.

The polydopamine coating is formed by spontaneous oxidative copolymerization of the dopamine on the surface of the substrate. Compared with traditional chemical modification methods, polydopamine can adhere to the surface of most materials without destroying the matrix structure. In addition, strong adhesion is formed between the polydopamine-encapsulated nanofiller and the polymer [13]. The covalent bonds are formed between the dicarboxylic anhydride of PI and the amine groups of polydopamine, further improving the compatibility of carbon nitride and the PI matrix.

In this work, the $\mathrm{g}-\mathrm{C}_{3} \mathrm{~N}_{4}$ composites were prepared from melamine through thermal condensation, and then carbon nitride nanosheets (CNNS) were prepared using the ultrasonic stripping method. Carbon nitride nanosheets modified by polydopamine (DCNNS) were prepared by self-polymerization of dopamine in a weak alkali environment, and then PI composite films with various CNNS and DCNNS were prepared by solution casting. The microstructure, dielectric, and breakdown properties of the composite films were investigated.

\section{Materials and Methods}

\subsection{Materials}

Melamine was purchased from Anhui Jinhe Co., Ltd. (Chuzhou, China). 4,4-oxydianiline (ODA) was purchased from Tianjin Guangfu Fine Chemical Research Institute (Tianjin, China). Pyromellitic dianhydride (PMDA) was purchased from Beijing Chemical Factory (Beijing, China). Dimethylacetamide (DMAc) was purchased from Beijing Innochem Science \& Technology Co., Ltd. (Beijing, China). Tris(hydroxymethyl)aminomethane hydrochloride (Tris- $\mathrm{HCl}$ ) and dopamine hydrochloride were purchased from Alfa Aesar Co., Ltd. (Shanghai, China). All reagents were used as received.

\subsection{Sample Preparation}

Preparation of the CNNS: Melamine powder covered with thin aluminum foil was heated to $500{ }^{\circ} \mathrm{C}$ with a heating rate of $3{ }^{\circ} \mathrm{C} \cdot \mathrm{min}^{-1}$ in a muffle furnace, and the temperature was maintained at $550{ }^{\circ} \mathrm{C}$ for $4 \mathrm{~h}$. After cooling to room temperature, the bulk g- $\mathrm{C}_{3} \mathrm{~N}_{4}$ was obtained. The ground bulk $\mathrm{g}-\mathrm{C}_{3} \mathrm{~N}_{4}(10 \mathrm{~g})$ was added into $1 \mathrm{~L}$ of deionized water and then stirred with a high-speed mixer at a speed of 13,000 rpm for $2 \mathrm{~h}$, followed by 
ultrasonically treating for $48 \mathrm{~h}$. After standing for $5 \mathrm{~h}$, the exfoliated CNNS was left in the upper white suspension. After evaporating most of the water at $80{ }^{\circ} \mathrm{C}$, the upper suspension was concentrated from $1 \mathrm{~L}$ to $50 \mathrm{~mL}$, and then the CNNS powder was obtained through freeze-drying.

Preparation of the DCNNS: The CNNS powder $(4 \mathrm{~g})$ was ultrasonically dispersed in $100 \mathrm{~mL}$ of deionized water for $30 \mathrm{~min}$, and then $0.315 \mathrm{~g}$ of $\mathrm{Tri}-\mathrm{HCl}$ and $0.379 \mathrm{~g}$ of dopamine hydrochloride was added to the CNNS aqueous suspension. After adjusting the $\mathrm{pH}$ to 8.5 by $\mathrm{NaOH}$, the suspension was stirred for $4 \mathrm{~h}$ to complete the modification. Finally, the mixture was centrifuged and rinsed repeatedly 5 times followed by freeze-drying to obtain the DCNNS powder.

Preparation of the PI composite films: The PI/CNNS and PI/DCNNS composite films were prepared through a viscous prepolymer cast on the glass slide and the thermal imidization method. A certain amount of CNNS or DCNNS was ultrasonically dispersed in $30 \mathrm{~mL}$ of DMAC for $2 \mathrm{~h}$, and then equimolar proportions of $3.064 \mathrm{~g}$ of ODA and $3.34 \mathrm{~g}$ of PMDA were added and stirred until the ODA was dissolved completely. Subsequently, the mixture was stirred under a nitrogen flow for $8 \mathrm{~h}$, followed by degassing under vacuum for $2 \mathrm{~h}$. The solid content of the PAA/CNNS and PAA/DCNNS suspension was 18\%. After casting on a flat glass plate, the mixture was converted into films by scraping them with a glass rod, and then thermally imidized at $60{ }^{\circ} \mathrm{C}$ for $10 \mathrm{~h}, 120{ }^{\circ} \mathrm{C}, 200{ }^{\circ} \mathrm{C}, 250{ }^{\circ} \mathrm{C}$ and $320^{\circ} \mathrm{C}$ for $1 \mathrm{~h}$ each. After the sample was naturally cooled to room temperature, the yellow and transparent PI composite films were obtained and denoted as PI/CNNS- $X$ and PI/DCNNS-Y, where $\mathrm{X} \%$ and $Y \%$ stand for the weight percentage of the CNNS and DCNNS. The thickness of the PI composites was approximately $30 \mu \mathrm{m}$.

\subsection{Characterization and Measurement}

The fractured surface of the PI/CNNS and PI/DCNNS composite films were observed by scanning electron microscopy (SEM, SU8010, Hitachi, Tokyo, Japan) with an accelerating voltage of $10 \mathrm{kV}$. The surface element composition was determined by the X-ray photoelectron spectrometer (XPS, Thermo Scientific K-Alpha, Waltham, MA, USA) equipped with an $\mathrm{Al} \mathrm{Ka} X$-ray source under an operating pressure below $8 \times 10^{-10} \mathrm{~Pa}$. The dielectric properties were tested by precision dielectric test apparatus (Novocontrol Concept 80, Montabaur, Germany). The dielectric breakdown strength $\left(E_{b}\right)$ was tested using a voltage-withstand testing device (HCDJC; Beijing Huace Testing Instrument Co. Ltd., Beijing, China) at ambient temperature, with an increasing alternating voltage of $0.5 \mathrm{kV} / \mathrm{s}$. The specimens were sandwiched between two copper rod electrodes with diameters of $25 \mathrm{~mm}$ and immersed in pure silicone oil to prevent surface flashover.

\section{Results and Discussions}

\subsection{Structure of the CNNS and DCNNS}

The photographs of the CNNS and DCNNS are shown in Figure 1a. It can be seen that the color of the CNNS powder is dark-yellow, while it changes to gray-brown when coated with polydopamine. As shown in Figure 1b, the DCNNS can form a very stable suspension in the DMAc, and no noticeable precipitate was observed even after $24 \mathrm{~h}$. In contrast, the CNNS were very unstable in the DMAc, as all the CNNS settled to the bottom after $24 \mathrm{~h}$. Since polydopamine with many hydroxyl groups is coated on the surfaces of the nanosheets, the DCNNS can form hydrogen bonds with the DMAc, which effectively improves the dispersion and stability of the nanosheets in the solvent.

XPS measurement was used to investigate the surface chemical composition of the elements in the CNNS and DCNNS. As compared between Figure 1c,f, both the CNNS and DCNNS contained the elements $\mathrm{C}, \mathrm{O}$, and $\mathrm{N}$, while the DCNNS had more O element as compared to the CNNS. Owing to the numerous oxygen-containing functional groups, the content of the $\mathrm{O}$ element increased from $3.28 \%$ to $7.44 \%$, and the $\mathrm{C} / \mathrm{O}$ ratio decreased from 12.4 to 6.3 after the polydopamine was coated on the nanosheets. In Figure $1 \mathrm{~d}$, the C1s spectra of both the CNNS and DCNNS contained two peaks at $284.8 \mathrm{eV}$ and $288.0 \mathrm{eV}$, 
which were assigned to $\mathrm{C}-\mathrm{C}$ and $\mathrm{N}-\mathrm{C}=\mathrm{N}$, respectively. The dominant peak of $\mathrm{N}-\mathrm{C}=\mathrm{N}$ originated from the aromatic nitrogen heterocyclic structure of the $g-C_{3} N_{4}$ [29]. However, one more peak at $286.1 \mathrm{eV}$ related to the $\mathrm{C}-\mathrm{O}$ peak was found in the spectrum of the DCNNS, which should be attributed to the amidogen and phenolic hydroxyl from the polydopamine. In Figure 1e, the N1s spectrum of the CNNS presented four component peaks, $\mathrm{C}=\mathrm{N}-\mathrm{C}$ at $398.6 \mathrm{eV}, \mathrm{N}-(\mathrm{C})_{3}$ at $400.1 \mathrm{eV}, \mathrm{N}-\mathrm{H}$ at $401.2 \mathrm{eV}$, and a heterocyclic charging effect of $404.5 \mathrm{eV}$ [30]. In contrast to the CNNS, the DCNNS had the same peak, and the peak intensity of the $\mathrm{C}=\mathrm{N}-\mathrm{C}$ was relatively low, which can be attributed to the adhesion of the polydopamine on the surface of the CNNS, which reduced the $\mathrm{N}$ element content detected on the surface of the CNNS. The results mentioned above illustrate the successful attachment of the dopamine to the surface of the CNNS.

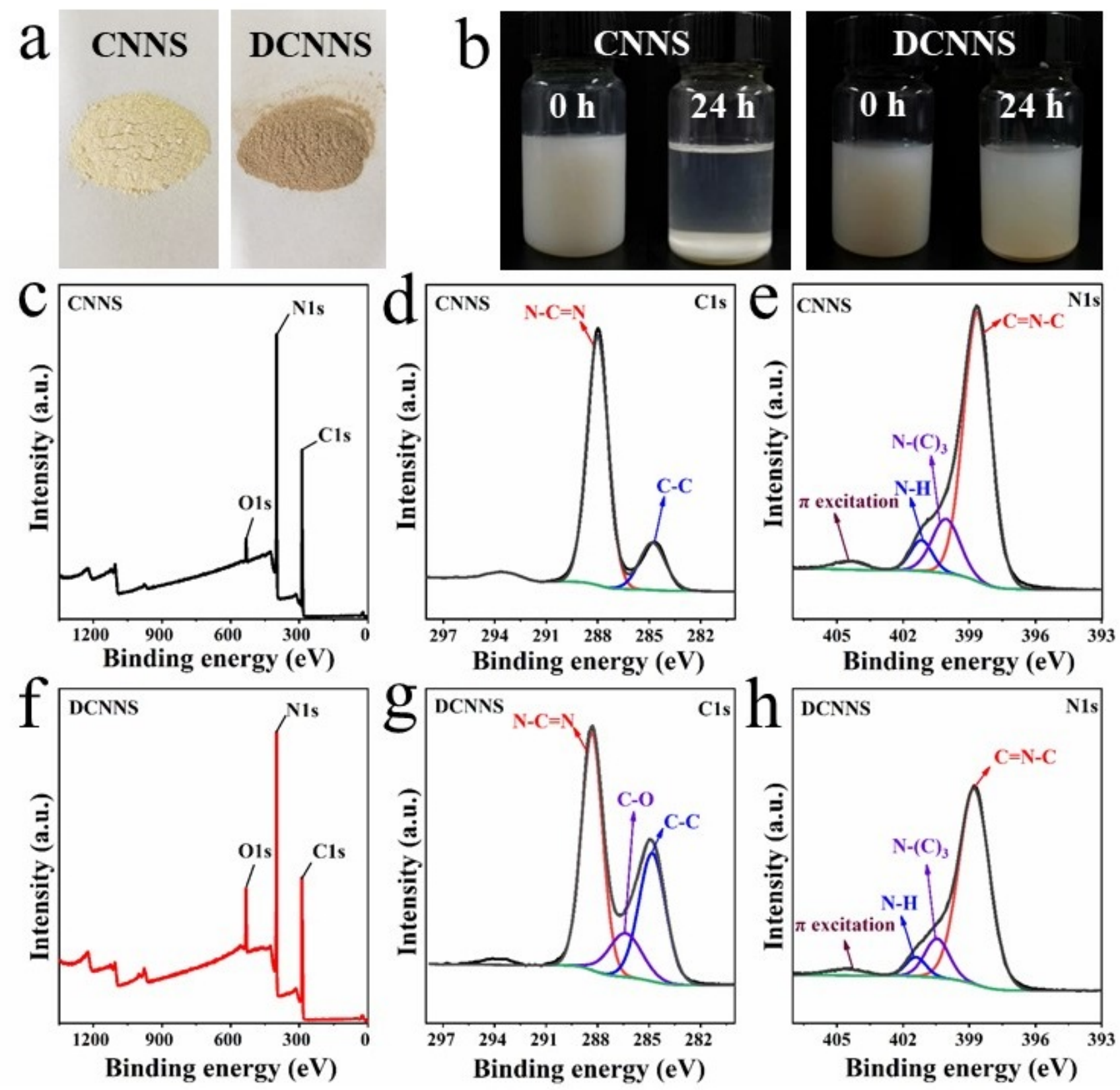

Figure 1. The photographs of (a) CNNS and DCNNS powder; (b) dispersing stability of CNNS and DCNNS in DMAC; XPS (c) wide-scan, (d) C1s and (e) N1s core-level spectra of CNNS; XPS (f) wide-scan, (g) C1s and (h) N1s core-level spectra of DCNNS. 


\subsection{Fractured Surface Morphologies}

The SEM images of the fracture surface for the PI composite films are shown in Figure 2. For the PI/CNNS composite films, some voids and defects can be seen in the composites, indicating the poor interfacial compatibility between the CNNS and the PI that becomes worse with higher filler content. As for the PI/DCNNS composites, no voids or defects can be seen in the composites with $0.25 \mathrm{wt} \%$ and $0.5 \mathrm{wt} \%$ filler contents. Moreover, some voids and defects were observed in the composites with $0.75 \mathrm{wt} \%$ and $1.0 \mathrm{wt} \%$, but still much fewer than those in the PI/CNNS composites with the same filler content. Only when the specific gravity of the DCNNS reached $1.0 \mathrm{wt} \%$ did a small number of protrusions appear, while the PI film with the CNNS added did cause filler agglomeration at $0.75 \mathrm{wt} \%$. This can be attributed to the fact that the hydroxyl groups on the surface of the DCNNS can form hydrogen bonds with the PI matrix or covalent bonds with the carboxyl groups of polyamic acid (the medium product used during the synthesis of the PI). This provides a morphological basis for the better breakdown performance of the PI/DCNNS composites, as discussed below. Under the action of the high-voltage electric field, such structural defects in the composites might induce the distortion of the electric field, which would directly affect the breakdown characteristics of the composite materials.


Figure 2. SEM images of the fractured surface for PI composites with (a) $0.25 \mathrm{wt} \%$, (b) $0.5 \mathrm{wt} \%$, (c) $0.75 \mathrm{wt} \%$ and (d) $1.0 \mathrm{wt} \%$ CNNS and (e) $0.25 \mathrm{wt} \%$, (f) $0.5 \mathrm{wt} \%$, (g) $0.75 \mathrm{wt} \%$ and (h) $1.0 \mathrm{wt} \%$ DCNNS.

\subsection{Dielectric Performance}

Breakdown strength is an important parameter used to evaluate dielectric materials.

Due to differences in structure and process, the scatter of breakdown times and breakdown strength may be large even for identical specimens. The researchers found that the breakdown voltage obeyed statistical probability distribution under the test standard [31]. 
The Weibull distribution is a statistical distribution proposed by the Swedish physicist Weibull in the fatigue test of materials, the main feature of which is to find the weakest independent small unit in the material and to calculate it analytically [32]. It is generally believed that the breakdown of polymer-insulating material occurs at the weakest point of the polymer. Therefore, in dielectric physics, the Weibull distribution is commonly used for statistical analysis of the breakdown field strength of polymer-insulating materials under DC and AC voltages [33]. The statistical model of the Weibull distribution can be used to analyze the magnitude and dispersion of the breakdown field strength of dielectric materials and to obtain the stability analysis results of the breakdown of dielectric materials.

The breakdown strength of the CNNS and DCNNS composites were analyzed by two parameter Weibull distribution approaches, which reflected the probability of the material being broken down under a certain electric field and the probability of failure after a certain electric field action time, as depicted in this formula:

$$
P(E)=1-\exp \left[-\left(\frac{E}{E_{b}}\right)^{\beta}\right]
$$

where $P(E)$ is the cumulative probability of failure for electrical faults, $E$ is the breakdown field strength for each data point, $E_{b}$ is the characteristic breakdown field strength where the cumulative failure probability is $63 \%$ for the polymer, and $\beta$ is the Weibull shape parameter used to assess the dispersion of the experimental data. In this experiment, for each sample, 11 data points were taken for testing to estimate the corresponding Weibull breakdown strengths.

Figure 3a shows the Weibull distribution DC breakdown strength of the pure PI and PI composite films. As shown in Figure 3a, the breakdown strength of all the PI/CNNS composite films was a little higher than that of the pure PI $\left(\sim 179 \mathrm{kV} \mathrm{mm}^{-1}\right)$. Nevertheless, all the PI/DCNNS composite films exhibited much higher breakdown strength than the PI/CNNS composite films with the same filler content, certainly significantly higher than the pure PI. In addition, as the content of DCNNS increased, the breakdown strength of the PI/DCNNS composite films first increased and then decreased. The PI/DCNNS composite film containing $0.5 \mathrm{wt} \%$ DCNNS showed the highest breakdown strength of $\sim 300 \mathrm{kV} / \mathrm{mm}$, which is $67.6 \%$ and $14.5 \%$ higher than the pure PI and the PI/CNNS with the same filler content, respectively.
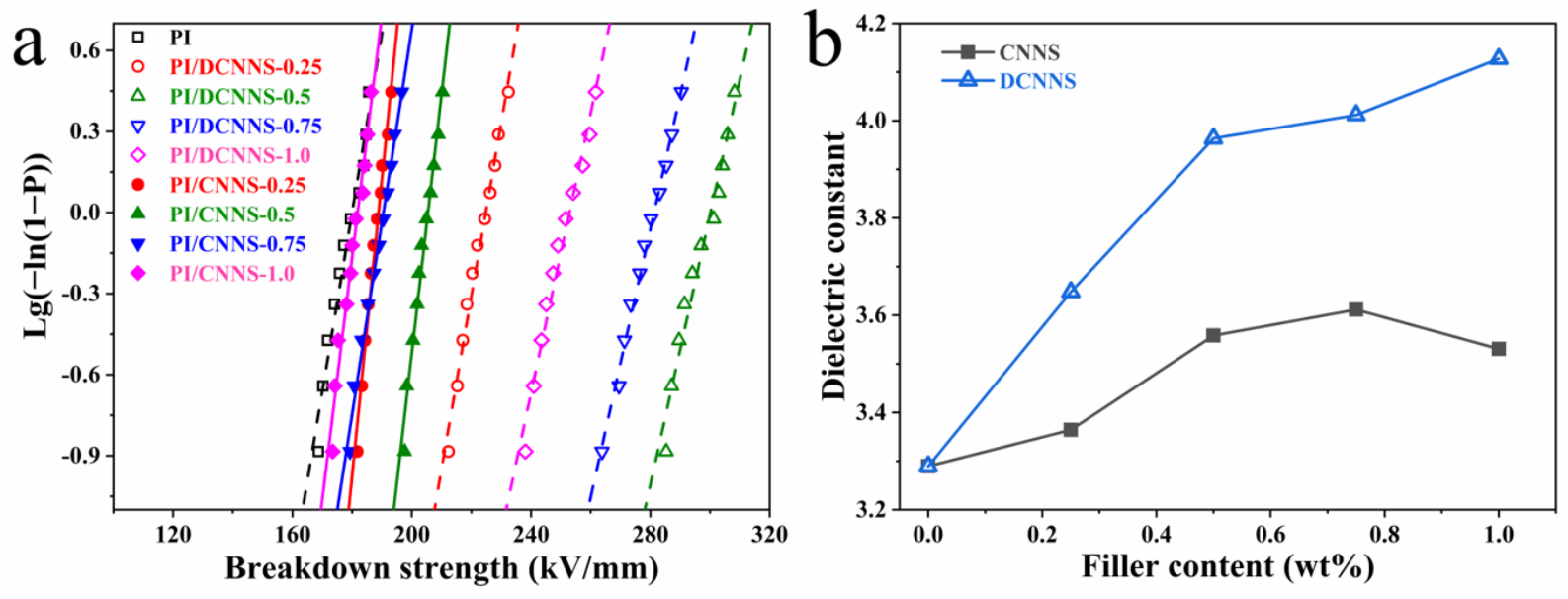

Figure 3. (a) Weibull distribution of electric strength and (b) dielectric constant change law of PI composites.

Owing to the high specific surface area of the two-dimensional nanomaterials, the interface between two-dimensional nanofillers and polymers occupies an important position even at low-filler content [34]. The interface layer surrounding the nanofiller is believed to dissipate the charge and improve the internal electric field distribution, while the dispersed 
nanofiller acts as a scattering center to help reduce the charge transport. The deep interface traps, introduced by incorporating the nanosheets, can capture carriers, leading to a decrease in mobility and thus an increase in the electrical strength at the working frequency. Compared with the PI/CNNS composite films, the stronger interfacial interaction results in much fewer defects in the PI/DCNNS composite films, and the tight combination of the PI and nanosheets also reduced the fluidity of the PI macromolecular chain and the carrier transport. Furthermore, more polar groups on the surface of the DCNNS enhanced the electron scattering. Therefore, a higher breakdown strength for the PI/DCNNS composite films was observed. The decrease in breakdown strength for filler content above $0.5 \mathrm{wt} \%$ should be due to the formation of the filler agglomerations in the PI matrix.

Moreover, the dielectric constant of PI composite films with various filler contents at $1 \mathrm{kHz}$ is shown in Figure 3b. All the PI/DCNNS composite films exhibited a higher dielectric constant than the PI/CNNS composite films with the same filler content, which should also be attributed to the stronger filler-matrix interactions and better filler dispersion.

\section{Conclusions}

In this work, the DCNNS were prepared using ultrasonic stripping of the bulk g- $\mathrm{C}_{3} \mathrm{~N}_{4}$ followed by polydopamine modification, which was confirmed by XPS. PI composite films with various contents of CNNS and DCNNS were prepared via the in-situ polymerization method. The modification of the $\mathrm{g}-\mathrm{C}_{3} \mathrm{~N}_{4}$ by polydopamine was revealed to strengthen the interfacial compatibility between the PI matrix and the DCNNS, and reduce the defects in the composites, resulting in an improvement in breakdown strength. Compared with the pure PI film, the PI/DCNNS composite films showed increased dielectric constant and a much higher breakdown strength. The PI/DCNNS composite film with $0.5 \mathrm{wt} \%$ DCNNS showed an increase in breakdown strength by $67.6 \%$ and $14.5 \%$ as compared to the pure $\mathrm{PI}$ and the PI/CNNS composite film with the same filler content, respectively. Therefore, we provided a simple and convenient method to prepare high-voltage insulating materials with excellent breakdown strength and good dielectric properties by adding only a small amount of nanosheets.

Author Contributions: Conceptualization, S.H. (Shaojian He); Data curation, Y.D., Z.W. and S.H. (Shouchao Huo); Formal analysis, Y.D. and Z.W.; Funding acquisition, J.L. and S.H. (Shaojian He); Investigation, Y.D. and S.H. (Shouchao Huo); Resources, J.L.; Supervision, J.L. and S.H. (Shaojian He); Writing-original draft, Y.D.; Writing—review and editing, S.H. (Shaojian He). All authors have read and agreed to the published version of the manuscript.

Funding: This work was supported by the National Natural Science Foundation of China [grant numbers 51973057, 51773058].

Institutional Review Board Statement: Not applicable.

Data Availability Statement: Not applicable.

Acknowledgments: The authors would like to thank the National Natural Science Foundation of China [grant numbers: 51973057, 51773058] for the financial support in completing this work.

Conflicts of Interest: The authors declare no conflict of interest.

\section{References}

1. Wan, B.Q.; Li, H.Y.; Xiao, Y.H.; Yue, S.S.; Liu, Y.Y.; Zhang, Q.W. Enhanced dielectric and energy storage properties of BaTiO 3 nanofiber/polyimide composites by controlling surface defects of $\mathrm{BaTiO}_{3}$ nanofibers. Appl. Surf. Sci. 2020, 501, 144243. [CrossRef]

2. Chen, J.; Zhang, X.; Yang, X.; Li, C.; Wang, Y.; Chen, W. High Breakdown Strength and Energy Storage Density in Aligned $\mathrm{SrTiO}_{3} @ \mathrm{SiO}_{2}$ Core-Shell Platelets Incorporated Polymer Composites. Membranes 2021, 11, 756. [CrossRef] [PubMed]

3. Cai, Z.M.; Wang, X.H.; Luo, B.C.; Hong, W.; Wu, L.W.; Li, L.T. Nanocomposites with enhanced dielectric permittivity and breakdown strength by microstructure design of nanofillers. Compos. Sci. Technol. 2017, 151, 109-114. [CrossRef]

4. Li, L.L.; Zhou, B.; Ye, J.F.; Wu, W.; Wen, F.; Xie, Y.C.; Bass, P.; Xu, Z.; Wang, L.W.; Wang, G.F.; et al. Enhanced dielectric and energy-storage performance of nanocomposites using interface-modified anti-ferroelectric fillers. J. Alloys Compd. 2020, 831, 154770. [CrossRef] 
5. Zhao, H.; Yang, C.; Li, N.; Yin, J.H.; Feng, Y.; Liu, Y.Y.; Li, J.L.; Li, Y.P.; Yue, D.; Zhu, C.C.; et al. Electrical and mechanical properties of polyimide composite films reinforced by ultralong titanate nanotubes. Surf. Coat. Technol. 2019, 360, 13-19. [CrossRef]

6. Yin, P.; Shi, Z.; Sun, L.; Xie, P.; Dastan, D.; Sun, K.; Fan, R. Improved breakdown strengths and energy storage properties of polyimide composites: The effect of internal interfaces of $\mathrm{C} / \mathrm{SiO}_{2}$ hybrid nanoparticles. Polym. Compos. 2021, 42, 3000-3010. [CrossRef]

7. Ai, D.; Li, H.; Zhou, Y.; Ren, L.; Han, Z.; Yao, B.; Zhou, W.; Zhao, L.; Xu, J.; Wang, Q. Tuning Nanofillers in In Situ Prepared Polyimide Nanocomposites for High-Temperature Capacitive Energy Storage. Adv. Energy Mater. 2020, 10, 1903881. [CrossRef]

8. Li, F.R.; Zhao, J.Y.; Guo, H.Q.; Gao, L.X. Enhanced Energy Storage Performance of Polyimide-based Nanocomposites by Introducing Two-dimensional Nanosheets. Acta Polym. Sin. 2020, 51, 295-302. [CrossRef]

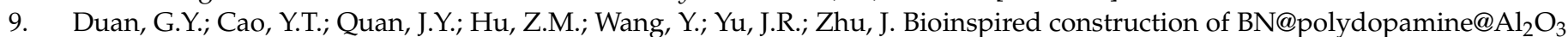
fillers for preparation of a polyimide dielectric composite with enhanced thermal conductivity and breakdown strength. J. Mater. Sci. 2020, 55, 8170-8184. [CrossRef]

10. He, S.J.; Hu, J.B.; Zhang, C.; Wang, J.Q.; Chen, L.; Bian, X.M.; Lin, J.; Du, X.Z. Performance improvement in nano-alumina filled silicone rubber composites by using vinyl tri-methoxysilane. Polym. Test. 2018, 67, 295-301. [CrossRef]

11. Sundar, U.; Lao, Z.; Cook-Chennault, K. Enhanced Dielectric Permittivity of Optimized Surface Modified of Barium Titanate Nanocomposites. Polymers 2020, 12, 827. [CrossRef] [PubMed]

12. He, S.J.; He, T.F.; Wang, J.Q.; Wu, X.H.; Xue, Y.; Zhang, L.Q.; Lin, J. A novel method to prepare acrylonitrile-butadiene rubber/clay nanocomposites by compounding with clay gel. Compos. Part B Eng. 2019, 167, 356-361. [CrossRef]

13. Qin, S.L.; Qiu, S.H.; Cui, M.J.; Dai, Z.D.; Zhao, H.C.; Wang, L.P. Synthesis and properties of polyimide nanocomposite containing dopamine-modified graphene oxide. High Perform. Polym. 2019, 31, 331-340. [CrossRef]

14. Chen, X.; Wang, J.Q.; Zhang, C.; Yang, W.; Lin, J.; Bian, X.M.; He, S.J. Performance of silicone rubber composites using boron nitride to replace alumina tri-hydrate. High Volt. 2021, 6, 480-486. [CrossRef]

15. Zhu, Y.; Yao, H.; Jiang, P.; Wu, J.; Zhu, X.; Huang, X. Two-Dimensional High-k Nanosheets for Dielectric Polymer Nanocomposites with Ultrahigh Discharged Energy Density. J. Phys. Chem. C 2018, 122, 18282-18293. [CrossRef]

16. Zhang, Y.-H.; Dang, Z.-M.; Xin, J.H.; Daoud, W.A.; Ji, J.-H.; Liu, Y.; Fei, B.; Li, Y.; Wu, J.; Yang, S.; et al. Dielectric Properties of Polyimide-Mica Hybrid Films. Macromol. Rapid Comm. 2005, 26, 1473-1477. [CrossRef]

17. He, S.J.; Luo, C.M.; Zheng, Y.Z.; Xue, Y.; Song, X.P.; Lin, J. Improvement in the charge dissipation performance of epoxy resin composites by incorporating amino-modified boron nitride nanosheets. Mater. Lett. 2021, 298, 130009. [CrossRef]

18. Xue, Y.; Wang, H.; Li, X.; Chen, Y. Synergy boost thermal conductivity through the design of vertically aligned 3D boron nitride and graphene hybrids in silicone rubber under low loading. Mater. Lett. 2020, 281, 128596. [CrossRef]

19. Liao, Y.F.; Weng, Y.X.; Wang, J.Q.; Zhou, H.F.; Lin, J.; He, S.J. Silicone rubber composites with high breakdown strength and low dielectric loss based on polydopamine coated mica. Polymers 2019, 11, 2030. [CrossRef]

20. Gaddam, S.K.; Pothu, R.; Boddula, R. Graphitic carbon nitride (g-C3N4) reinforced polymer nanocomposite systems-A review. Polym. Compos. 2020, 41, 430-442. [CrossRef]

21. Xu, S.; Wang, J.; Lin, L.; Valério, A.; He, D. Synthesis of carbon nitride nanosheets with tunable size by hydrothermal method for tetracycline degradation. Mater. Lett. 2020, 264, 127005. [CrossRef]

22. Kang, S.; He, M.; Chen, M.; Wang, J.; Zheng, L.; Chang, X.; Duan, H.; Sun, D.; Dong, M.; Cui, L. Ultrafast plasma immersion strategy for rational modulation of oxygen-containing and amino groups in graphitic carbon nitride. Carbon 2020, 159, 51-64. [CrossRef]

23. Zhu, L.; You, L.J.; Shi, Z.X.; Song, H.J.; Li, S.J. An investigation on the graphitic carbon nitride reinforced polyimide composite and evaluation of its tribological properties. J. Appl. Polym. Sci. 2017, 134, 45403. [CrossRef]

24. Wang, Y.Y.; Zhang, X.; Ding, X.; Zhang, P.; Shu, M.T.; Zhang, Q.; Gong, Y.; Zheng, K.; Tian, X.Y. Imidization-induced carbon nitride nanosheets orientation towards highly thermally conductive polyimide film with superior flexibility and electrical insulation. Compos. Part B Eng. 2020, 199, 108267. [CrossRef]

25. He, S.J.; Wang, J.Q.; Hu, J.B.; Zhou, H.F.; Nguyen, H.; Luo, C.M.; Lin, J. Silicone rubber composites incorporating graphitic carbon nitride and modified by vinyl tri-methoxysilane. Polym. Test. 2019, 79, 106005-106010. [CrossRef]

26. Song, H.J.; Li, L.Y.; Yang, J.; Jia, X.H. Fabrication of Polydopamine-Modified Carbon Fabric/Polyimide Composites With Enhanced Mechanical and Tribological Properties. Polym. Compos. 2019, 40, 1911-1918. [CrossRef]

27. Su, C.; Xue, F.; Xu, F.L.; Li, T.S.; Xin, Y.S.; Wang, M.M. Tribological Properties of Surface-Modified Graphene Filled Carbon Fabric/Polyimide Composites. J. Macromol. Sci. Part B 2019, 58, 603-618. [CrossRef]

28. McCaffrey, M.; Hones, H.; Cook, J.; Krchnavek, R.; Xue, W. Geometric analysis of dielectric failures in polyimide/silicon dioxide nanocomposites. Polym. Eng. Sci. 2019, 59, 1897-1904. [CrossRef]

29. Yu, Z.X.; Li, F.; Yang, Q.B.; Shi, H.; Chen, Q.; Xu, M. Nature-Mimic Method To Fabricate Polydopamine/Graphitic Carbon Nitride for Enhancing Photocatalytic Degradation Performance. ACS Sustain. Chem. Eng. 2017, 5, 7840-7850. [CrossRef]

30. Xia, P.; Mingjin, L.; Cheng, B.; Yu, J.; Zhang, L. Dopamine Modified g-C3N4 and Its Enhanced Visible-Light Photocatalytic H2-Production Activity. ACS Sustain. Chem. Eng. 2018, 6, 8945-8953. [CrossRef]

31. Kim, C.; Jiang, P.K.; Liu, F.; Hyon, S.; Ri, M.G.; Yu, Y.; Ho, M. Investigation on dielectric breakdown behavior of thermally aged cross-linked polyethylene cable insulation. Polym. Test. 2019, 80, 106045. [CrossRef] 
32. Zhao, Y.K.; Zhang, G.Q.; Guo, R.R.; Yang, F.Y. The Breakdown Characteristics of Thermostable Insulation Materials under High-Frequency Square Waveform. IEEE Trans. Dielectr. Electr. Insul. 2019, 26, 1073-1080. [CrossRef]

33. Silau, H.; Stabell, N.B.; Petersen, F.R.; Pham, M.; Yu, L.Y.; Skov, A.L. Weibull Analysis of Electrical Breakdown Strength as an Effective Means of Evaluating Elastomer Thin Film Quality. Adv. Eng. Mater. 2018, 20, 1800241. [CrossRef]

34. Beier, C.W.; Sanders, J.M.; Brutchey, R.L. Improved Breakdown Strength and Energy Density in Thin-Film Polyimide Nanocomposites with Small Barium Strontium Titanate Nanocrystal Fillers. J. Phys. Chem. C 2013, 117, 6958-6965. [CrossRef] 